\title{
Research on Computer-aided Teaching System of Landscape Design
}

\author{
Jun Hu \\ Wuhan Bioengineering Institute, Wuhan, Hubei 430403, China
}

Keywords: landscape design; computer-aided technology; teaching system

\begin{abstract}
The role of computer-aided technology in education has been recognized, and it can solve some defects in the teaching of landscape architecture. How to apply computer-aided technology to landscape design teaching properly is an urgent problem. This paper aims to develop a teaching system for computer drawing methods to describe the main garden elements in landscape design. The teaching system is positioned as an auxiliary teaching tool, and is a special teaching method for drawing garden computer drawings outside the classroom teaching.
\end{abstract}

\section{Introduction}

With the rapid development of the garden industry, computer aided design (CAD) has been widely applied to the current landscape design work. Therefore, in the garden major of domestic colleges and universities, computer aided design has also become a very important application course, and its teaching work is mainly around the use of general drawing software to complete the task of computer aided drawing. Currently, there are two main problems encountered in the teaching of computer aided design in landscape architecture: one the one hand, There are few data on computer drawing in gardens on the market and in the network, and classroom learning has become the only way for students to learn computer drawing in gardens, which gives the students a great limit to their study; on the other hand, due to the limitations of the curriculum, in classroom teaching, there is not enough time to explain the drawing of garden elements. Under these circumstances, if the teacher can arrange the computer drawing method of garden drawings into written materials, or even record the image materials for the students, it will undoubtedly help greatly improve the computer drawing level of students majoring in landscape architecture. The research goal of this paper is to develop a teaching system for computer drawing methods to describe the main garden elements in landscape design. The teaching system is positioned as an auxiliary teaching tool, and is a special teaching method for drawing garden computer drawings outside the classroom teaching.

\section{Assistant Software for Garden Design Teaching}

In the field of garden design, drawing software such as AutoCAD, 3dsMax, SketchUp, Photoshop are is rapidly replacing drawing pens and artboards as the main design tools. Compared with hand-painted drawings, these software have very obvious advantages in landscape planning and design, so they can be utilized in garden design teaching system.

\subsection{AutoCAD}

AutoCAD software by Autodesk Company is the most widely used software tool for computer-aided drafting and design. In the garden design, landscape planning, landscape architecture and other industries, its graphics file drawing commands and editing tools could efficiently help to complete the overall planning, the green design, and the corresponding construction drawing of the plan, and is also the basis for the later effect processing and rendering of the effect diagram.

\subsection{3dsMax}

3dsMax is the most widely used and popular 3D modeling, animation, and rendering software on the PC platform. In garden design and landscape planning, it is mainly used for graphical modeling, 
since it has a more realistic effect on the material imparted to the object.

\subsection{SketchUp}

SketchUp is also called "Sketch Master", which is a software for creating, sharing, and presenting models. In garden design, SketchUp is usually applied combining with AutoCAD to work together to complete the rendering of the garden design. The garden design plan draw by AutoCAD can be introduced into SketchUp and then use create three-dimensional model, and finally converted to Photoshop to carry on post rendering.

\subsection{Photoshop}

Photoshop is a graphic design and editing software, which has very powerful image processing capabilities. In garden design, usually use its powerful image processing function to complete the garden graphic design scheme drawn in AutoCAD, and 3D graphics post-drawing effect processing drawn in 3dsMax.

\section{Development of Garden Design Teaching System}

\subsection{Overall design}

The computer aided garden design teaching system consists of three parts: garden design teaching essentials module, garden design element library module and garden design gallery module. In the teaching essentials, the overall layout of each element is the same problem as each feature library, but the former is based on theoretical texts, while the latter is mainly based on pictures and materials, and the both part complement each other to explain the problems of various elements in garden design; similarly, the planning and design of various green spaces and the garden design library are unified issues, however, The former is mainly based on explanation, while the latter provides a wealth of picture materials. In short, garden design teaching essentials module, garden design element library module and garden design gallery module well complement each other, and together they form a relatively complete teaching software system.

The application framework of computer aided garden design teaching system is shown as Figure 1.

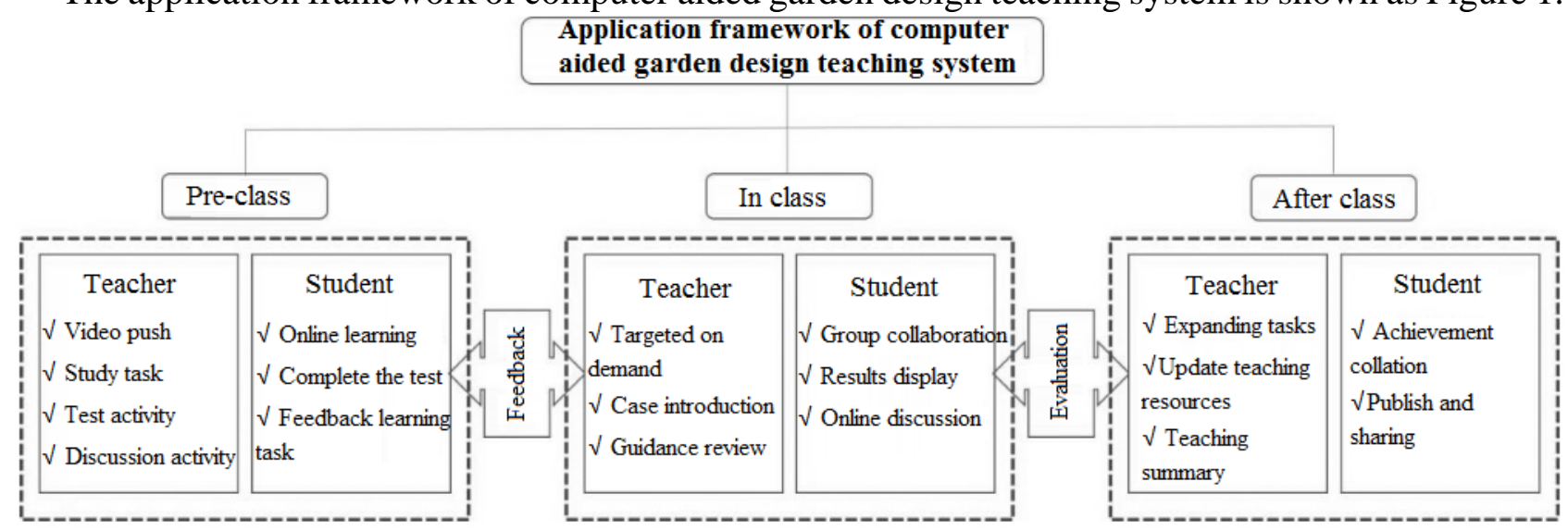

Figure 1. Application framework of garden design teaching system

\subsection{Software platform}

The development of garden design teaching system is based on Autoware.5.2, supported by Macromedia Company, because it has the following advantages:

(1) Object-oriented creation. It provides an intuitive icon control interface, so designers could write widgets with icons, and use the logical structure of the various icons to make the entire system, so that replace complex programming languages and improve the visibility of multimedia system production.

(2) Cross-platform architecture. Whether on Windows or Macintosh platforms, Autoware 
provides almost exactly the same working environment, which makes it a rare multimedia authoring tool that can be easily ported to both platforms.

(3) Flexible interaction and rich system variables and functions. It provides the most flexible and colorful way to interact. For multimedia, especially the interactive teaching system, human-computer interactive assessment is an important aspect of the entire system. Autoware provides more than 10 ways of interaction for developers to choose, as well as a wealth of functions and variables, to collect, store, and analyze data.

(4) Efficient multimedia integration environment. Through its own multimedia management mechanism, developers can make full use of text, sound, images, animation, video and other content to achieve the entire multimedia system. Autoware provides management of the memory library, so it makes huge multimedia information independent of the application, to not only reduces the memory space occupied by the program, but also improve development efficiency.

(5) Standard application interface. For users with special requirements, Autoware provides corresponding standard interface to extend existing system features.

(6) Multimedia network transmission technology. The Shockware component by Autoware can apply all its features to Internet.

(7) Modular design. Pipeline program in Autoware convenient icon design makes modular programming easy, so as to avoid a lot of duplication of labor.

\subsection{Garden design teaching essentials module}

Table 1. Text script of garden design teaching essentials module

\begin{tabular}{|c|c|c|c|}
\hline Knowledge unit & Knowledge point & Material form & Teaching objectives \\
\hline \multirow{4}{*}{ Introduction } & Garden history track & Image, text & Understand \\
\hline & Garden development trend & Image, text & $\begin{array}{l}\text { Comprehend and } \\
\text { application }\end{array}$ \\
\hline & $\begin{array}{l}\text { Introduction to western } \\
\text { garden design }\end{array}$ & Text & Understand \\
\hline & How to learn garden design & Text & Understand \\
\hline $\begin{array}{c}\text { Chapter I: Basis and } \\
\text { principle }\end{array}$ & Basis, principle & Text & Comprehend \\
\hline \multirow{3}{*}{$\begin{array}{l}\text { Chapter II: Garden } \\
\text { design theory }\end{array}$} & Garden form & Image, text & Analysis and application \\
\hline & Perception of scenery & Image, text & Comprehend \\
\hline & $\begin{array}{l}\text { Principle of landscape } \\
\text { composition }\end{array}$ & $\begin{array}{c}\text { Animation, } \\
\text { commentary, text, } \\
\text { music }\end{array}$ & $\begin{array}{l}\text { Comprehend, analysis } \\
\text { and application }\end{array}$ \\
\hline \multirow{2}{*}{$\begin{array}{c}\text { Chapter III: Planting } \\
\text { design }\end{array}$} & Planting design of flowers & Image, text & $\begin{array}{l}\text { Comprehend and } \\
\text { application }\end{array}$ \\
\hline & $\begin{array}{c}\text { Planting design of the trees } \\
\text { and shrubs }\end{array}$ & Image, text, animation & $\begin{array}{l}\text { Comprehend and } \\
\text { application }\end{array}$ \\
\hline \multirow{4}{*}{$\begin{array}{l}\text { Chapter IV: Layout of } \\
\text { the elements }\end{array}$} & Topographic treatment & Text & Comprehend \\
\hline & Road square layout & Image, text & Comprehend \\
\hline & $\begin{array}{c}\text { Small equipment layout } \\
\text { Bureau }\end{array}$ & Image, text & $\begin{array}{c}\text { Comprehend and } \\
\text { application }\end{array}$ \\
\hline & Garden plant layout & Image, text & $\begin{array}{l}\text { Comprehend and } \\
\text { application }\end{array}$ \\
\hline \multirow{2}{*}{$\begin{array}{l}\text { Chapter V: Planning and } \\
\text { design of various types of } \\
\text { green space }\end{array}$} & Comprehensive park & Image, text & Comprehend \\
\hline & Botanical Garden & Image, text & Comprehend \\
\hline
\end{tabular}

Garden design teaching essentials are the outline of teaching, where a classroom demonstration can be carried out. This module is designed based on reference materials for garden design, and combined with teaching activities and the development trend of modern garden design. According to the analysis of the garden teaching curriculum, different chapters, different teaching purposes, and different levels of difficulty are handled differently. The content of the text is intended to be concise, 
and the key knowledge is explained in detail. In addition, in order to increase persuasiveness, multiple forms of expression is utilized, such as animated demonstration, key explanation, etc. Since it is used in the classroom, although it is a classroom presentation material, it can be also used as self-study materials for students.

The text script of garden design teaching essentials module is shown as Table 1.

\subsection{Garden design element library module}

Garden design element library module contains all the elements of the garden, including terrain, plants, buildings, road square, and small garden ornaments, etc. This part focuses on the form and design points of the five elements. The terrain includes a picture of the form of a landscape, as well as brief description of design layout; plant material library includes pictures of common plants in Northeast and North China and plant plane representation; architectural material library includes pictures of various landscape architecture forms, such as the hall, the building, the pavilion, and the corridor, etc.; road square material library includes the layout of roads and squares, and the materials and forms of storehouse; small garden ornaments include rockery, stone carving, flower rack, garden chair, railings, sculpture, garden lantern form and its common layout.

This module of the computer aided garden design teaching system is designed to allow students to fully understand and master the specific forms and layout of the various elements of the garden. There's a lot of picture material in this module to be retrieved freely, so it is a valuable reference material for students to learn and give lectures to teachers.

The frame of garden design element library module is shown as Figure 2.

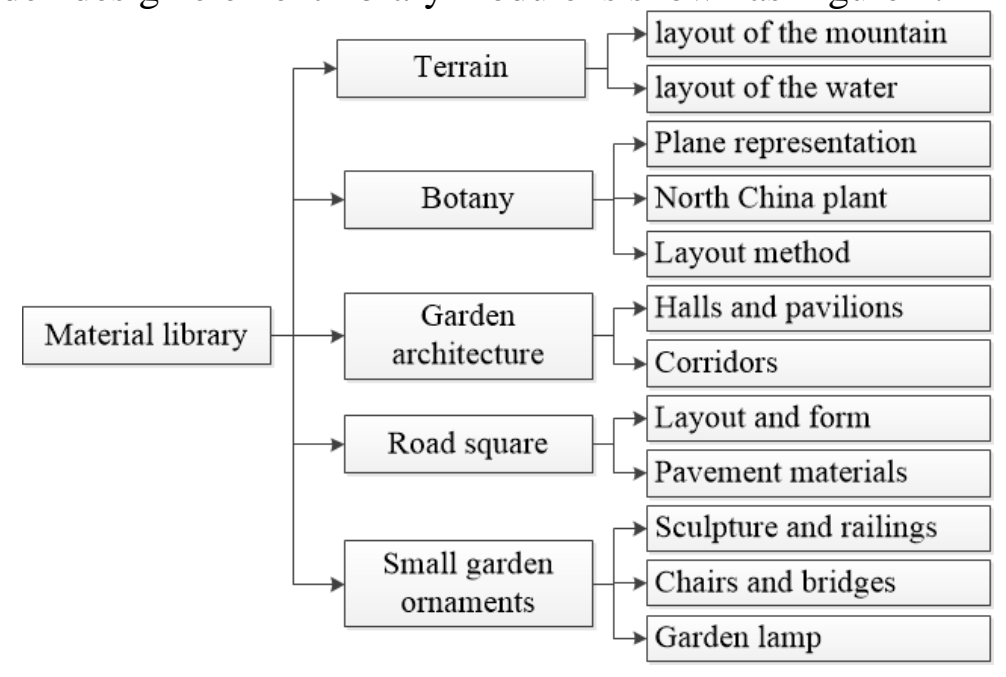

Figure 2. Frame of garden design element library module

The text script of garden design element library module is shown as Table 2.

Table 2. Text script of garden design element library module

\begin{tabular}{|c|c|c|c|}
\hline Knowledge unit & Knowledge point & Material form & Teaching objectives \\
\hline terrain & $\begin{array}{l}\text { The expression of } \\
\text { landscape in the garden }\end{array}$ & $\begin{array}{l}\text { Image and text } \\
\text { commentary }\end{array}$ & Comprehend \\
\hline Botany & $\begin{array}{c}\text { Plant morphology and } \\
\text { habits }\end{array}$ & $\begin{array}{c}\text { Image and text } \\
\text { commentary }\end{array}$ & Application \\
\hline Garden architecture & $\begin{array}{c}\text { Architectural form and } \\
\text { characteristics }\end{array}$ & $\begin{array}{c}\text { Image and text } \\
\text { commentary }\end{array}$ & $\begin{array}{c}\text { Comprehend and } \\
\text { application }\end{array}$ \\
\hline Road square & $\begin{array}{c}\text { Various forms and } \\
\text { materials }\end{array}$ & $\begin{array}{c}\text { Image and text } \\
\text { commentary }\end{array}$ & $\begin{array}{c}\text { Comprehend and } \\
\text { application }\end{array}$ \\
\hline small garden ornaments & $\begin{array}{c}\text { Structure, form and } \\
\text { material }\end{array}$ & $\begin{array}{l}\text { Image and text } \\
\text { commentary }\end{array}$ & Application \\
\hline
\end{tabular}

\subsection{Garden design gallery module}

Garden design gallery module provides a rich garden design gallery, including Chinese classical 
gardens, modern Chinese gardens, western classical gardens, western modern gardens, as well as various types of green spaces such as children's parks, memorial parks, scenic spots, etc. Among them, Chinese classical gardens include some famous gardens like Jiangnan gardens and Beijing gardens, which are classified as royal garden (e.g. Old Summer Palace, the Summer Palace, etc.), house garden, mausoleum, temple, temple view garden, and landscape garden, etc. Through vivid garden design material, this module helps students to deeply understand the characteristics of the Chinese and Western gardens, and critically inherit the art of garden creation. In addition, this module can also be used to explain the students before their internship, helping improving the effect of practice. For instance, by entering a plan of the Summer Palace and pictures of all the attractions, click anywhere to get the corresponding pictures and commentary.

The text script of garden design gallery module e is shown as Table 3.

Table 3. Text script of garden design gallery module

\begin{tabular}{|c|c|c|c|}
\hline Knowledge unit & Knowledge point & Material form & Teaching objectives \\
\hline \multirow{5}{*}{ Garden design gallery } & $\begin{array}{c}\text { Chinese classical } \\
\text { gardens }\end{array}$ & $\begin{array}{l}\text { Image, music and text } \\
\text { introduction }\end{array}$ & $\begin{array}{l}\text { Understand and } \\
\text { comprehend }\end{array}$ \\
\hline & $\begin{array}{l}\text { Modern Chinese } \\
\text { gardens }\end{array}$ & $\begin{array}{l}\text { Image, music and text } \\
\text { introduction }\end{array}$ & $\begin{array}{l}\text { Understand and } \\
\text { comprehend }\end{array}$ \\
\hline & $\begin{array}{l}\text { Western classical } \\
\text { garden }\end{array}$ & $\begin{array}{l}\text { Image, music and text } \\
\text { introduction }\end{array}$ & $\begin{array}{l}\text { Understand and } \\
\text { comprehend }\end{array}$ \\
\hline & $\begin{array}{l}\text { Western modern } \\
\text { gardens }\end{array}$ & $\begin{array}{l}\text { Image, music and text } \\
\text { introduction }\end{array}$ & $\begin{array}{l}\text { Understand and } \\
\text { comprehend }\end{array}$ \\
\hline & $\begin{array}{c}\text { Various types of green } \\
\text { spaces }\end{array}$ & $\begin{array}{l}\text { Image, music and text } \\
\text { introduction }\end{array}$ & $\begin{array}{l}\text { Understand and } \\
\text { comprehend }\end{array}$ \\
\hline
\end{tabular}

\section{Teaching content of garden design system}

By the help of the computer aided garden design teaching system, teachers can carry out teaching of garden design courses. The teaching content in garden design system contain three parts: sketcher drawing, rendering modeling and post rendering processing.

\subsection{Sketcher drawing}

The system uses AutoCAD for sketcher drawing teaching. In addition to Basic drawing and modification commands, teachers can explain in combination with plans, perspectives, sections, and legends. The commands include:

a) Basic parameters general settings and operation interface introduction;

b) Creation of straight line, multi-line, multi segment line, spline line and circular rectangle with graphic creation toolbar;

c) Extension, pruning, array, fixed number and distance commands by extension, pruning, array, fixed number and distance command;

d) Layers, lines and colors, text annotation settings, etc.

Finally, after AutoCAD teaching, teachers had better explain the points for attention of AutoCAD importing 3dsMax and SketchUp.

\subsection{Rendering modeling}

Select 3dsMax and SketchUp as the main tools to explain how to conduct garden 3D modeling. 3dsMax software is powerful, and due to its delicate rendering material performance, 3dsMax has become an indispensable software in 3D modeling. Moreover, on surface modeling, 3dsMax is more practical than SketchUp. Whereas SketchUp has the advantanges of fast drawing and easy modification. Therefore, in landscape modeling, these two software are usually combined to use, to give full play to their own advantages. 3dsMax teaching content mainly includes:

a) 3dsMax operation interface introduction, menu bar, view navigation and general settings; 
b) 3dsMax creation of basic graphics by graphic creation tool, including geometry, cylinder, etc.;

c) 3dsMax graphic modification toolbar operation;

d) 3dsMax graphic export and primitive combination.

In addition to drawing skills and modifications operation, software shortcuts also need to be introduced. Particularly, in the teaching of these two software, the actual model case is of great significance, such as creation and drawing of bookcase, pavilion, gallery, shelf, etc.

\subsection{Post rendering processing}

Compared to 3D image processing, post-processing and retouching are equally important. Post-material rendering will make the renderings more realistic and vivid. In the past image post processing, Photoshop is often used as post-configuration and processing, because of its powerful software features. The teaching content by Photoshop is as follow:

a) Photoshop software modification and garden plane rendering;

b) Photoshop software modification and garden scene rendering.

Overall speaking, computer aided garden design teaching courses are mainly based on AutoCAD, 3dsMax, SketchUp and Photoshop, to carry out teaching of sketcher drawing, rendering modeling and post rendering processing.

\section{Conclusion}

In the design of computer aided instruction system, there are still many aspects worth trying. Through the planning and design of landscape architecture by computer technology, students can master new digital design tools, and strengthen the students' logical thinking ability. In addition, computer aided software improves students' three-dimensional space design ability and practical ability, and inspires the creativity of the students, therefore, in the classroom of landscape planning and design, computer aided technology and related software should be fully utilized.

\section{References}

[1] Wang Y P, Yang T, Zhai Y, et al. Discuss on the practice teaching system of garden Technology Specialty in Higher Vocational Colleges[J]. Ningxia Forestry Communication, 2015.

[2] Karen Smith. Cultivating innovative learning and teaching cultures: a question of garden design[J]. Teaching in Higher Education, 2011, 16(4):427-438.

[3] Yuan M X, Fang D F. Discussion on Practice Teaching Course Reform of Garden Design in Higher Vocational and Special Education[J]. Journal of Yangling Vocational \& Technical College, 2007.

[4] Liu H B. Design and Realization of the Computer Aided Teaching System[J]. International Journal of Digital Content Technology \& Its Applic, 2013.

[5] Zhi-Hui Y U. Practice and Results of Project Teaching in Computer-aided Garden Design Course Teaching Mode[J]. Journal of Anhui Agricultural Sciences, 2013.

[6] Li G. On Computer-aided Gardening Design in the Major of Garden Design in Vocational Colleges[J]. Journal of Wuhu Vocational Institute of Technology, 2010. 